\title{
Dendritic Gold Substrates for Surface-Enhanced Raman Spectroscopy
}

\author{
Kym M. Watling and Gregory A. Hope \\ School of Science \\ Griffith University, Nathan, Queensland, 4111 \\ Email: k.watling@griffith.edu.au
}

\begin{abstract}
Gold surface-enhanced Raman scattering (SERS) substrates were prepared by oxidation/reduction cycling in

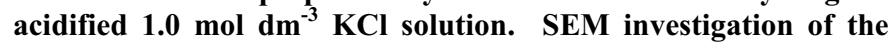
SERS-activated gold surface revealed the formation of clusters of nanoscale dendrites. The SERS activity generated by the treatment enabled the detection of the vibrational modes of adsorbates present at sub-monolayer coverages and the observation of surface species present during active leaching in cyanide and thiosulfate solutions.
\end{abstract}

Keywords-SERS; gold; dendrites.

\section{INTRODUCTION}

Surface-enhanced Raman scattering (SERS) is a phenomenon by which certain metals, prepared with specific morphologies, greatly enhance the vibrational Raman effect for molecules on, or close to, the metal surface [1]. Enhanced signal intensities can range from $10^{3}$ to $10^{14}$ times that of normal Raman scatter allowing submonolayer detection of adsorbates, detection of trace amounts of analyte and, under certain experimental conditions, the detection of single molecules $[2,3]$. The coinage metals silver, copper and gold display the most intense enhancement, with other metals including platinum, rhodium, iron, cobalt and nickel enhancing to lesser degree [4].

SERS theories propose that the effect is due to resonance of applied radiation with the surface plasmons of the metal substrate, with the frequency of the surface plasmons dependent on the size and shape of the nanoparticles [1]. When the condition of resonance is achieved by matching the irradiation frequency to that of the surface plasmons, an enormous electromagnetic field is generated at the substrate surface, enhancing the Raman scatter of molecules within the field. Regions of strongest enhancement due to this 'electromagnetic effect' occur in spaces, known as 'hot spots' between nanoparticles [1]. A further resonance Raman-like enhancement, known as the 'chemical effect', occurs due to chemical interactions between adsorbed species and the surface atoms [4].

The morphology of SERS substrates is critical to their function. The two most commonly used (and studied) SERS substrate morphologies are spherical or spheroidal nanoparticles, which occur in colloidal SERS substrates; and roughened surfaces with grating-like periodicity, such as oxidation/reduction cycled electrodes and lithographically prepared gratings [4]. Electrochemical oxidation/reduction cycling was the first method of activating metals as SERS substrates and was the method by which the SERS effect was discovered [5]. The random grating generated by electrochemical roughening allows momentum to be conserved between the incoming photons and the surface plasmons, satisfying conditions for resonance [4].

Studies of surface plasmon excitation in fractal surfaces have featured in the literature over the last decade [6-8]. Studies modeling dendritic structures as Koch curve fractals predicted that maximum SERS activity would arise from molecules adsorbed at high apexes of dendritic aggregates [8] The first use of a dendritic nanostructure as a substrate for SERS enhancement using silver has recently been reported, in which silver dendrites grown by self-assembly during reduction of $\mathrm{AgNO}_{3}$ on a copper film were used for the detection of 4-pyridinethiol [9]. Gold dendritic nanostructures have appeared in recent literature in applications such as semiconductor supported biomimetric superhydrophobicity substrates [10] and have been seen to play a role in the formation of silicon nanowires [11]. Here we present a novel gold dendritic SERS substrate, which we have used routinely for our investigations of sulfur electroadsorption [12], dissolution of gold in chloride media [13], and leaching in cyanide [13] and thiosulfate lixiviant systems [14].

\section{EXPERIMENTAL}

A fine gold electrode (Johnson Matthey 99.5\%) was abraded on P1200 SiC paper then sonicated in ultrapure water for $2 \mathrm{~min}$. The electrode was then placed in a furnace at $4500^{\circ} \mathrm{C}$ for at least $30 \mathrm{~min}$ to remove any surface contamination. On removal from the furnace, the electrode was quenched and stored in ultrapure water from a Permutit Hi-Pure Water System with typical resistivity of $18 \mathrm{M} \Omega \mathrm{cm}$ prior to electrochemical activation.

Ammoniacal copper(II) sodium thiosulfate leach solutions were prepared using AR grade reagents. The solutions were mixed by firstly dissolving copper sulfate then adding ammonia. Sodium thiosulfate was added last to avoid complexation of thiosulfate with copper(II). The solution was oxygenated prior to introduction to the cell by vigorous shaking with air for $2 \mathrm{~min}$ in an oversized container in order to avoid loss of ammonia. The concentration was $0.1 \mathrm{~mol} \mathrm{dm}^{-3}$ in $\mathrm{Na}_{2} \mathrm{~S}_{2} \mathrm{O}_{3}, 0.4 \mathrm{~mol} \mathrm{dm}^{-3}$ in $\mathrm{NH}_{3}$ and $0.01 \mathrm{~mol} \mathrm{dm}^{-3}$ in $\mathrm{CuSO}_{4}$. 


\section{A. SERS Surface Activation}

The SERS surface was generated by applying a square wave pulse to the gold electrode in $1.0 \mathrm{~mol} \mathrm{dm} \mathrm{dm}^{-3} \mathrm{KCl}$ acidified to $\mathrm{pH} 1$ with $\mathrm{HCl}$, in equilibrium with air. The three-electrode electrochemical cell used consisted of the gold working electrode, a platinum wire counter electrode and a Cypress systems $\mathrm{EE} 008 \mathrm{Ag} / \mathrm{AgCl} / 3 \mathrm{M} \mathrm{KCl}$ reference electrode. The ambient room temperature was $22^{\circ} \mathrm{C}$, resulting in an $\mathrm{Ag} / \mathrm{AgCl}$ reference potential of $0.210 \mathrm{~V}$ on the standard hydrogen electrode (SHE) scale [15]. Potentials are reported relative to the $\mathrm{Ag} / \mathrm{AgCl}$ reference. A Pine RDE4 potentiostat was used to apply potential to the system, under the control of a custombuilt square wave frequency generator. The frequency generator featured a duty cycle in which the deposition step was 20 ms longer than the dissolution step to reduce the loss of gold by diffusion of tetrachloroaurate from the electrochemical interface. The electrode was subjected to pulses at upper and lower potentials of 1.0 and $-0.5 \mathrm{~V}$ at $1 \mathrm{~Hz}$ over a 5 min period, with the cycle ending at the at the lower potential. After SERS activation, the electrode was gently rinsed and stored in ultrapure water prior to use. The electrode exhibited a bronze coloration and a hydrophilic surface after activation.

\section{B. Raman Instrumentation}

SERS spectra were acquired on a Renishaw system 100 Raman fibre optic spectrometer, using $632.8 \mathrm{~nm}$ excitation from a $\mathrm{HeNe}$ laser. The laser light was delivered through an optical fibre and focused through the collection lens to a measured spot size of $50 \mu \mathrm{m}$, with $6 \mathrm{~mW}$ power at the sample. Raman scattered radiation was collected through an ultra-long working distance $\times 20$ Olympus LMP Plan Fl lens with a numeric aperture of 0.4 and focused through two super notch filters onto the spectrometer receiving fibre. The Raman shifted signals from the single pass grating spectrometer were detected using a Peltier-cooled CCD detector with spectral resolution of $2 \mathrm{~cm}^{-1}$. The spectrometer was referenced to the $520 \mathrm{~cm}^{-1}$ lattice vibration of silicon. SERS spectra were accumulated in static mode, with scans centered at $670 \mathrm{~cm}^{-1}$. Leaching spectra were recorded at the mixed potential in quiescent solution in equilibrium with air in a custom-designed five-necked borosilicate electrochemical cell with an optically flat transparent window.

\section{Secondary Electron Imaging and Analysis}

Electrodes were imaged using scanning secondary electron microscopy (SEM) and analysed for composition using backscattered electron imaging and energy dispersive x-ray analysis (EDX) using a FEI Quanta 200 Environmental SEM at the QUT/GU Analytical Electron Microscopy Facility.

\section{Kinetic Studies}

Kinetic studies were undertaken using a rotating cylindrical fine gold stub (Johnson Matthey $99.5 \%$ ) of $6.8 \mathrm{~mm}$ diameter, using a Pine MX Rotator to maintain a rotation speed of 300 rpm. The stub was abraded on P1200 SiC paper prior to ultrasonication in ultrapure water. Gold concentrations were determined by Atomic Absorption Spectrophotometry (AAS), using a Varian A10 Spectrophotometer and gold lamp emission at $242.8 \mathrm{~nm}$. Gold standards for atomic absorption spectrophotometry were prepared from $\mathrm{Na}_{3} \mathrm{Au}\left(\mathrm{S}_{2} \mathrm{O}_{3}\right)_{2} .2 \mathrm{H}_{2} \mathrm{O}$ (AR, Aldrich) dissolved in the relevant sodium or ammonium thiosulfate leach matrix.

\section{RESULTS AND DISCUSSION}

Tian et al. documented oxidation / reduction cycle (ORC) roughening procedures for metals including $\mathrm{Ag}, \mathrm{Au}, \mathrm{Cu}, \mathrm{Pt}$, $\mathrm{Rh}, \mathrm{Fe}$ and Co [4]. Liu and co-workers slightly modified Tian's ORC for gold to optimize SERS enhancement of polypyrrole [16]. Their regime consisted of 25 cycles in 0.1 mol dm${ }^{-3} \mathrm{KCl}$ from $-0.28 \mathrm{~V}$ (holding $10 \mathrm{~s}$ ) to $1.22 \mathrm{~V}$ vs $\mathrm{Ag} / \mathrm{AgCl}$ (holding $5 \mathrm{~s}$ ) with a sweep rate of $500 \mathrm{mVs}^{-1}$. Scanning electron micrographs of Liu's optimized surface showed nanoscale roughening on the top of macroscopic ridges on the electrode surface [17]. Atomic force micrographs showed the roughening to consist of small raised nodules with diameters in the range of $10-100 \mathrm{~nm}$.

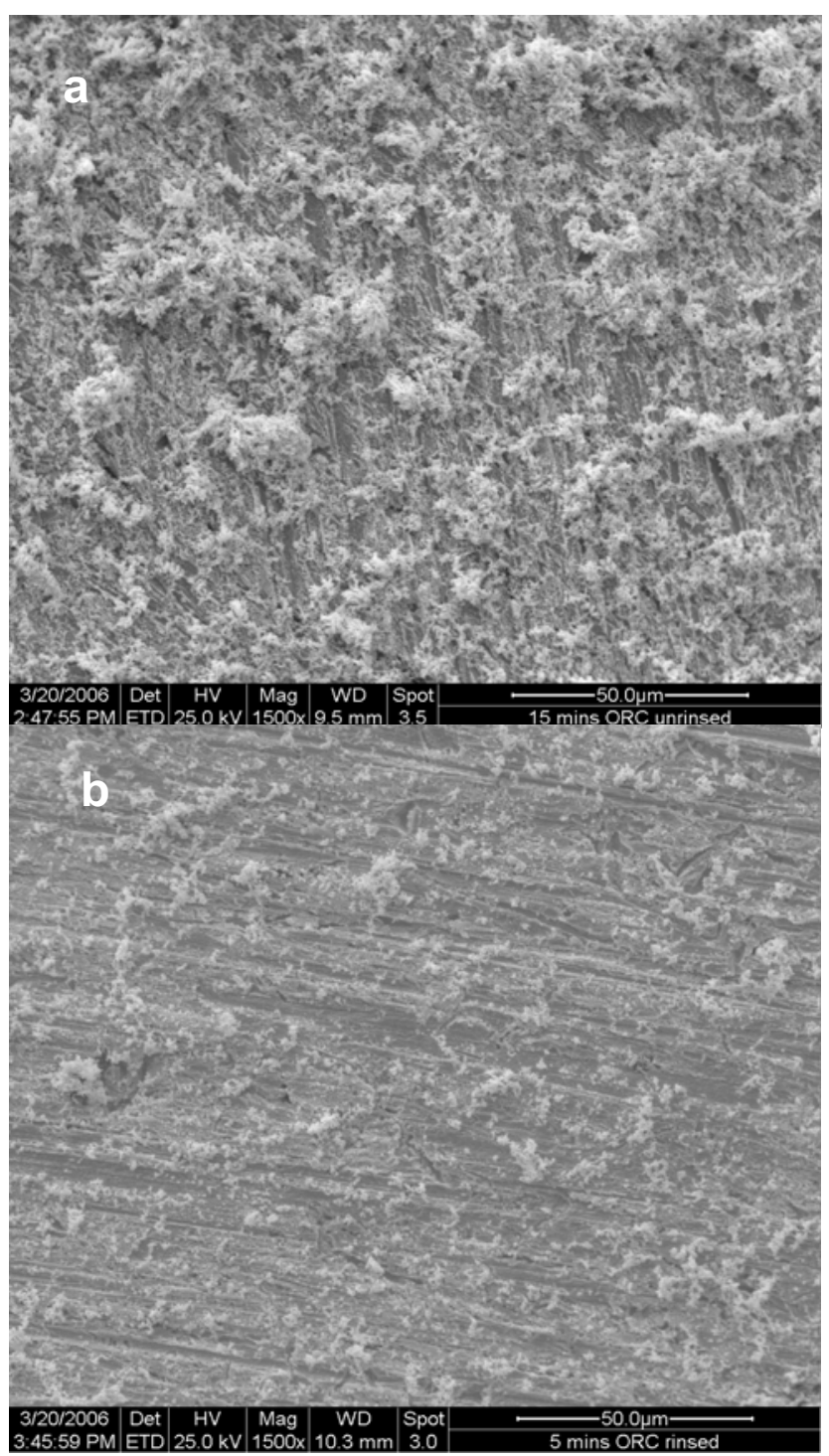

Figure 1: SEM images of SERS electrodes - a) excessive electrodeposit, 15 min ORC with soaking to minimise loss of surface structures, b) standard preparation, 5 min ORC with rinsing. 
The SERS activation techniques of Tian and Liu both utilize $0.1 \mathrm{~mol} \mathrm{dm}^{-3} \mathrm{KCl}$ solutions. In this work, application of a square-wave pulsing regime in a more concentrated and acidified $1.0 \mathrm{~mol} \mathrm{dm}{ }^{-3} \mathrm{KCl}$ solution was seen to generate an efficient SERS substrate composed of electrodeposited dendrites of nanoscale dimensions.

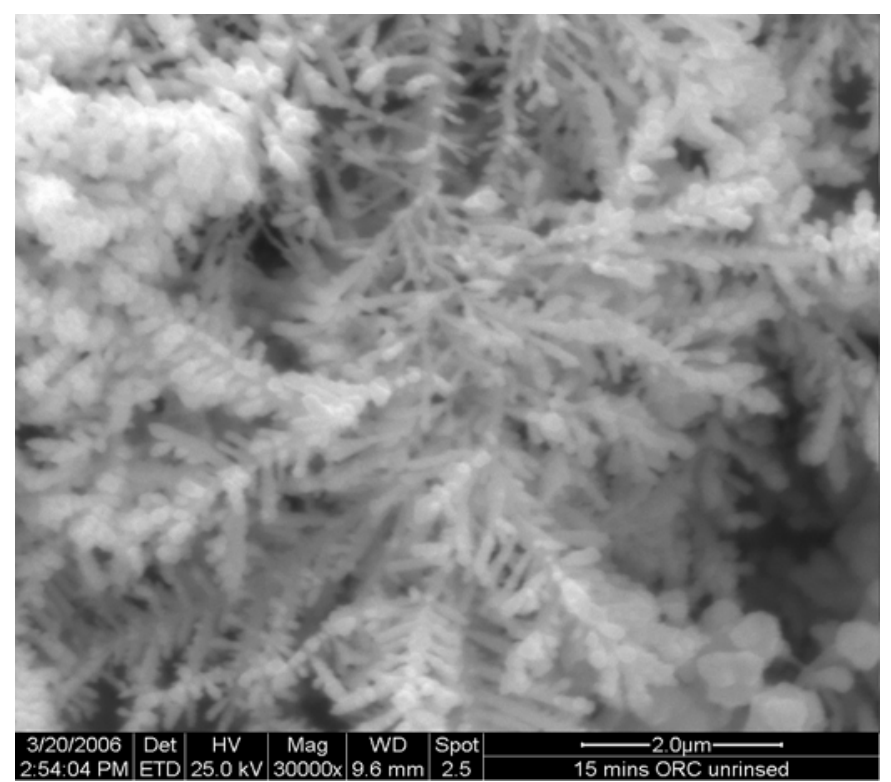

Figure 2: SEM image of dendritic nanostructures on a gold SERS oxidation/reduction cycled for $15 \mathrm{~min}$ in $1.0 \mathrm{~mol} \mathrm{dm}^{-3} \mathrm{KCl}$ at $\mathrm{pH} 1$.

\section{A. Secondary Electron Imaging and Analysis}

Gold SERS electrodes routinely used for dissolution studies were characterized by scanning electron microscopy and compositional analysis by energy dispersive X-ray (EDX) analysis. One electrode was subjected to the standard ORC activation regime and one to an excessive treatment to maximize the electrodeposited growth. The standard electrode was rinsed and stored in ultrapure water for $10 \mathrm{~min}$ as per normal conditions, then air dried. The second electrode was subjected to pulsing for $15 \mathrm{~min}$. This electrode was not rinsed, so as to minimize disruption of the fragile electrogenerated surface features, and was stored in ultrapure water to remove residual electrolyte from the roughened surface. This electrode displayed a dark brown rust-colored coating, which was easily removed from previous samples during rinsing.

Figure 1a presents an SEM image of the excessively prepared electrode, while Figure $1 \mathrm{~b}$ shows the standard preparation. The images show both samples to be covered in a surface deposit. The excessively prepared surface has a heavier coverage of the deposit, which appears at this magnification to be in the form of fibrous conglomerates. Linear striations from the $\mathrm{SiC}$ abrasion step can be seen in both images. The $50 \mu \mathrm{m}$ bar gives an indication of the density of the electrogenerated surface product irradiated by the HeNe laser spot of the same diameter.

Figure 2 shows a higher magnification of a typical section of the excessively prepared sample. The image clearly shows the fibrous conglomerates to be composed of dendrites. The dendrites consist of both fine and coarse structures, with features in the range of $10-100 \mathrm{~nm}$ associated with SERS enhancement [4]. The electrode subjected to the standard ORC procedure and rinsing showed lower coverage of dendritic outcrops and larger particle size.

Both the standard and excessively prepared samples were analysed for composition by EDX and electron backscatter analysis in the interest of determining the presence of residual $\mathrm{KCl}$ from the ORC process. Such evidence was not observed for either sample.

\section{B. SERS of Active Gold Leaching}

Figure 3 shows SERS spectra acquired over time during dissolution studies of gold in an ammoniacal copper(II) sodium thiosulfate leaching solution. In figure $3 \mathrm{a}$, two strong bands due to an adsorbed surface species appear within 5 min of immersion. A band at $1017 \mathrm{~cm}^{-1}$ appears in a similar position to that of the S-O stretching modes of $\mathrm{Au}\left(\mathrm{S}_{2} \mathrm{O}_{3}\right)_{2}{ }^{3-}$, while another at $378 \mathrm{~cm}^{-1}$ occurs at the same Raman shift wavenumber as the $\mathrm{S}-\mathrm{S}$ stretch in the tetrathionate ion, $\mathrm{S}_{4} \mathrm{O}_{6}{ }^{2-}$. The intensity of the bands has increased by $10 \mathrm{~min}$, as has the background of the scan. By $10 \mathrm{~min}$, a weak broad band is also seen to appear at $265 \mathrm{~cm}^{-1}$, a region in which Au-S stretching modes have previously been observed [18]. By $20 \mathrm{~min}$, the bands and SERS background reach a maximum intensity.

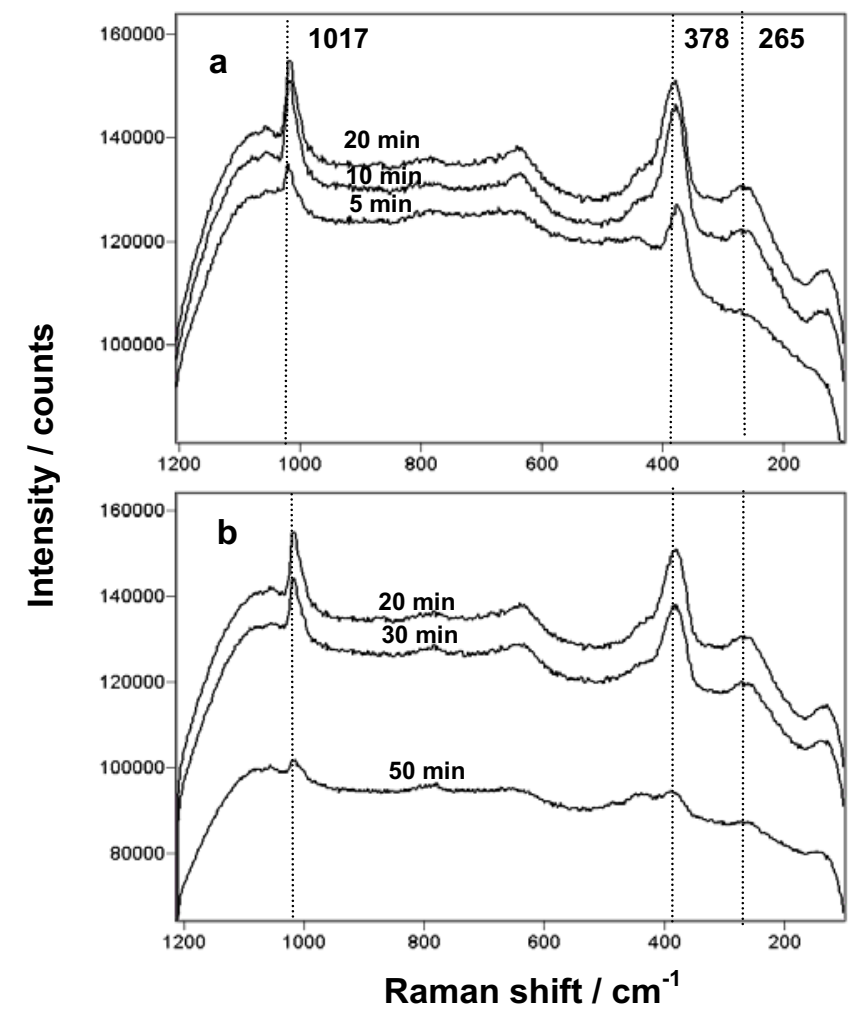

Figure 3: Time-evolved SERS spectra from dendritic gold surface leached in ammoniacal copper(II) sodium thiosulfate solution, a) evolution of signal to maximum at $20 \mathrm{~min}, \mathrm{~b}$ ) diminution of signal after $20 \mathrm{~min}$ 
Figure $3 \mathrm{~b}$ shows the diminution of both the Raman bands and SERS background by 30 and $50 \mathrm{~min}$, as compared with the 20 min scan. At 50 min a broad weak band is noted at $\sim 440 \mathrm{~cm}^{-1}$. This band occurs in the region in which a broad range of S-S modes are observed in an aged ammoniacal copper(II) sodium thiosulfate leach solution. The comparative increase in intensity of this mode compared to those of the surface product may indicate competition between the weakening SERS effect and the normal Raman scatter of the solution.

\section{SERS of Electroadsorbed Sulfur}

The dendritic gold electrode has been used to characterize the adsorption of sulfur on gold using SERS and electrochemical techniques. The SERS sensitivity of the dendritic substrate was sufficient to enable the detection of one third of a monolayer of sulfur on the gold surface [12]. The surface coverage of sulfur at the potentials at which the SERS spectra were acquired were determined by electrochemical oxidation of adsorbed sulfur to sulfate on smooth gold electrodes. The coverages acquired agreed with those found in STM studies of sulfur electroadsorption on gold [19].

\section{Dissolution Kinetics}

Evidence of continued dissolution of the gold surface after leaching for one hour was obtained using kinetic studies of the dissolution process. A polished rotating gold electrode of the same purity as the electrode used for SERS was leached in an identical thiosulfate solution over a $16 \mathrm{hr}$ period. Samples of the leach solution were extracted hourly for the first five hours and analysed by AAS to determine the rate of gold dissolution. The gold concentration was seen to increase linearly from one to five hours, with a dissolution rate of $8.3 \mu \mathrm{mol} \mathrm{m} \mathrm{m}^{-2} \mathrm{~s}^{-1}$ during this period. As the gold is seen to continue dissolving after 1 $\mathrm{hr}$, the diminution of SERS signal seen after 20 min leaching would appear to be due to the loss of SERS surface and not to a cessation of the leaching process.

\section{CONCLUSIONS}

The application of a square-wave oxidation / reduction cycle in acidified $1.0 \mathrm{~mol} \mathrm{dm}{ }^{-3} \mathrm{KCl}$ resulted in the formation of a novel dendritic gold SERS substrate. The concentration of $\mathrm{KCl}$ used in the activation process is ten times that used in the conventional electrochemical SERS activation procedures for gold, which produce a nanostructured roughened surface. The dendritic surface remained SERS active during active dissolution in an ammoniacal copper(II) sodium thiosulfate leach solution for up to $50 \mathrm{~min}$, with a maximum enhancement seen at $20 \mathrm{~min}$.

\section{ACKNOWLEDGMENT}

The authors would like give thanks to Professor Ron Woods and Dr. Matthew Jeffrey for their valued guidance, and to the Australian Research Council and the CRC for microTechnology for funding this work.

\section{REFERENCES}

[1] K. Kneipp, H. Kneipp, I. Itzkan, R. R. Dasari, and M. S. Feld, "Ultrasensitive Chemical Analysis by Raman Spectroscopy," Chem. Rev., vol. 99, pp. 2957-2975, 1999.

[2] K. Kneipp, Y. Wang, H. Kneipp, L. T. Perelman, I. Itzkan, R. R. Dasari, and M. S. Feld, "Single Molecule Detection Using Surface-Enhanced Raman Scattering (SERS)," Physical Review Letters, vol. 78, pp. 1667$1670,1997$.

[3] S. Nie and S. R. Emory, "Probing Single Molecules and Single Nanoparticles by Surface-Enhanced Raman Scattering," Science, vol. 275, pp. 1102-1106, 1997.

[4] Z. Q. Tian, "Surface-Enhanced Raman Scattering: From Noble to Transition Metals and from Rough Surfaces to Ordered Nanaostructures," J. Phys. Chem. B, vol. 106, pp. 9463-9483, 2002.

[5] M. Fleischmann, P. J. Hendra, and A. J. McQuillan, "Raman spectra of pyridine adsorbed at a silver electrode," Chemical Physics Letters, vol. 26, pp. 163-166, 1974.

[6] S. I. Bozhevolnyi, B. Vohnsen, A. V. Zayats, and I. I. Smolyaninov, "Fractal surface characterization: implications for plasmon polariton scattering," Surface Science,, vol. 356, pp. 268-274., 1996.

[7] J. A. Sanchez-Gil and J. V. Garcia-Ramos, "Calculations of the direct electromagnetic enhancement in suface enhanced Raman scattering on random self-affine fractal metal surfaces," Journal of Chemical Physics, vol. 108, pp. 317-325, 1998.

[8] M. Micic, N. Klymyshyn, and H. P. Lu, "Finite element method simulations of the near-field enhancement at the vicinity of fractal rough metallic surfaces," Journal of Physical Chemistry B, vol. 108, pp. 29392947, 2004.

[9] W. Song, Y. Cheng, H. Jia, W. Xu, and B. Zhao, "Surface enhanced Raman scattering based on silver dendrites substrate," Journal of Colloid and Interface Science, vol. 298, pp. 765-768, 2006.

[10] C.-H. Wang, Y.-Y. Song, J.-W. Zhao, and X.-H. Xia, "Semiconductor supported biomimetic superhydrophobic gold surfaces by the galvanic exchange reaction," Surface Science, vol. 600, pp. 38-42, 2006.

[11] K. Peng and J. Zhu, "Simultaneous gold deposition and formation of silicon nanowire arrays," Journal of Electroanalytical Chemistry, vol. 558, pp. 35-39, 2003.

[12] K. Watling, G. Parker, G. A. Hope, and R. Woods, "A SERS Investigation of the Interactionof Sulfur with Gold," ECS Transactions, vol. 2, pp. 61-72, 2006.

[13] K. Watling, G. A. Hope, and R. Woods, "SERS Investigation of Gold Dissolution in Chloride and Cyanide Media," Journal of The Electrochemical Society, vol. 152, pp. D103-D108, 2005.

[14] R. Woods, G. A. Hope, K. M. Watling, and M. I. Jeffrey, "A Spectroelectrochemical Study of Surface Species Formed in the Gold/Thiosulfate System," Journal of The Electrochemical Society, vol. 153, pp. D105-D113, 2006.

[15] H. Galster, pH measurement: Fundamentals, methods, applications, instrumentation. Weinheim: VCH, 1991.

[16] Y.-C. Liu, B.-J. Hwang, and W.-J. Jian, "Effect of preparation conditions for roughening gold substrate by oxidation-reduction cycle on the surface-enhanced Raman spectroscopy of polypyrrole," Materials Chemistry and Physics, vol. 73, pp. 129-134, 2002.

[17] Y.-C. Liu, C.-C. Wang, and C.-E. Tsai, "Effects of electrolytes used in roughening gold substrates by oxidation-reduction cycles on surfaceenhanced Raman scattering," Electrochemistry Communications, vol. 7, pp. 1345-1350, 2005.

[18] X. Gao, Y. Zhang, and M. J. Weaver, "Adsorption and electrooxidative pathways for sulfide on gold as probed by real-time surface-enhanced Raman spectroscopy," Langmuir, vol. 8, pp. 668-672, 1992.

[19] X. Gao, Y. Zhang, and M. J. Weaver, "Observing surface chemical transformations by atomic-resolution scanning tunneling microscopy: sulfide electrooxidation on $\mathrm{Au}(111)$," Journal of Physical Chemistry, vol. 96, pp. 4156-4159, 1992. 